\title{
Molecular-scale surface processes during the growth of calcite in the presence of manganese
}

\author{
J. M. Astilleros, ${ }^{1, *}$ C. M. Pina, ${ }^{1,2}$ L. FernándeZ-díaZ ${ }^{2}$ and A. Putnis ${ }^{1}$ \\ ${ }^{1}$ Institut für Mineralogie, Universität Münster, Corrensstrasse 24, D-48149, Münster Germany \\ ${ }^{2}$ Dpto. Cristalografía y Mineralogía, Universidad Complutense, 28040 Madrid, Spain
}

\begin{abstract}
This paper deals with the growth behaviour of the Mn-Ca- $\mathrm{CO}_{3}-\mathrm{H}_{2} \mathrm{O}$ solid solution-aqueous solution system on calcite $\{10 \overline{1} 4\}$ surfaces. This system represents a model example, which allows us to study the effect of a number of controlling factors on the crystallisation: (1) the supersaturation function, $\beta(\mathrm{x})$, and nucleation rate function, $J(x)$, for the $\mathrm{Mn}-\mathrm{Ca}-\mathrm{CO}_{3}-\mathrm{H}_{2} \mathrm{O}$ system, (2) the relationship of such functions to the molecular scale growth mechanisms operating on growing surfaces, and (3) the surface structure of the calcite $\{10 \overline{1} 4\}$ faces. In situ atomic force microscopy (AFM) growth experiments revealed a wide variety of surface phenomena, such as the transition between growth mechanisms, anisotropic changes in the step rates, and the influence of the Mn-bearing newly formed surface on subsequent growth (step stoppage followed by the formation of two-dimensional nuclei and the reproduction of the original calcite $\{10 \overline{1} 4\}$ surface microtopography). These phenomena result from the interplay between the controlling parameters and are explained in those terms.
\end{abstract}

\section{INTRODUCTION}

Calcite, because of its reactive surfaces and ubiquity in natural aqueous environments, is the most important carbonate controlling divalent metal mobility. Among the different surface metal uptake mechanisms, coprecipitation reactions and subsequent formation of $(\mathrm{M}, \mathrm{Ca}) \mathrm{CO}_{3}$ solid solutions (where $\mathrm{M}$ is a divalent cation) have been found to be significant in geochemical systems (Reeder, 1996; Tesoriero and Pankow, 1996; Böttcher, 1997; Temmam et al., 2000). Cations incorporated into the calcite structure from supersaturated solutions include a wide range of environmental contaminants (e.g., $\mathrm{Cd}^{2+}, \mathrm{Pb}^{2+}, \mathrm{Co}^{2+}, \mathrm{Zn}^{2+}$ ) and diagenetic tracers (e.g., $\mathrm{Mg}^{2+}$, $\left.\mathrm{Mn}^{2+}\right)$. The incorporation of such cations not only affects the composition of the growing carbonate, but also plays an important role in the crystallization process, evidenced by changes in growth rates, shape, and thickness of growth layers, etc. (Sangwal, 1993). In addition, the variability of morphologies and textures usually exhibited by natural and synthetic calcite is frequently attributed to the substitution of $\mathrm{Ca}^{2+}$ by other cations in the calcite structure (Parker et al., 1993; Fernández-Díaz et al., 1996; Temman et al., 2000). The study of the relationships between crystal morphology and chemical composition is, therefore, of special interest for understanding the formation of calcite in both geologic and biogenic environments.

Recently, considerable efforts have been made to understand the effect of different cations on the growth behaviour of calcite at a molecular scale. AFM observations have revealed a number of nanometric processes occurring on the calcite $\{10 \overline{1} 4\}$ surface, including the modification of the morphology of spirals and step dynamics, the anomalous thickening of certain growth steps, and the selective incorporation of cations in crystallographic non-equivalent sites on the surfaces (Paquette and

* Author to whom correspondence should be addressed (astiller@nwz.uni-muenster.de).
Reeder, 1995; Davis et al., 2000; Astilleros et al., 2000, 2002). It seems clear that all these phenomena are the result of the interplay between physicochemical conditions (i.e., composition of the aqueous solutions and their saturation states with respect to the crystallizing calcitic solid solution), the kinetics of the possible growth mechanisms (spiral growth, two dimensional nucleation, and continuous growth) operating at a molecular scale on the different faces of the crystal, and the surface structure of the growing face.

In this paper we present a study of the effect of $\mathrm{Mn}^{2+}$ on calcite $\{10 \overline{1} 4\}$ surfaces during growth. The specific thermodynamics of the $\mathrm{Mn}-\mathrm{Ca}-\mathrm{CO}_{3}-\mathrm{H}_{2} \mathrm{O}$ SS-AS (solid solution-aqueous solution) system, i.e., the non-ideality of the solid solution and the existence of miscibility gaps close to the endmembers (McBeath et al., 1998), together with the clear structural control exerted by calcite surfaces on Mn incorporation, makes this system a very suitable example to evaluate the influence of the factors that determine the actual growth behaviour of the $\mathrm{Mn}_{\mathrm{x}} \mathrm{Ca}_{1-\mathrm{x}} \mathrm{CO}_{3}$ solid solution. Our study includes (1) the evaluation of the supersaturation, $\beta(x)$, and nucleation rate, $J(x)$, functions for the Mn-Ca- $\mathrm{CO}_{3}-\mathrm{H}_{2} \mathrm{O}$ system on the basis of solid solution-aqueous solution theory, (2) the relationship of such functions to the operating growth mechanisms, and (3) the present knowledge about the surface structure of the calcite $\{10 \overline{1} 4\}$ faces. By considering these controlling parameters, we can interpret a number of molecular-scale surface phenomena observed using in situ atomic force microscopy (AFM) (e.g., anisotropic modification of step rates, changes in growth mechanisms, and an inhomogeneous covering of the surface, reproducing the original microtopographic features).

\section{CALCITE $\{10 \overline{1} 4\}$ SURFACES GROWING FROM $\mathrm{Ca}-\mathrm{Mn}-\mathrm{CO}_{3}$ AQUEOUS SOLUTIONS}

As a starting point for studying the growth of the calcite $\{10 \overline{1} 4\}$ face in the presence of $\mathrm{Mn}$, it is necessary to consider the thermodynamic properties of the $\mathrm{Mn}-\mathrm{Ca}-\mathrm{CO}_{3}-\mathrm{H}_{2} \mathrm{O}$ SS-AS 
system as well as the interrelation between the calcite $\{10 \overline{1} 4\}$ surface structure and the incorporation and adsorption behaviour of $\mathrm{Mn}$. In the following subsections, we will present: (1) a general study of the thermodynamics and kinetics of the Mn$\mathrm{Ca}-\mathrm{C}_{3}-\mathrm{H}_{2} \bullet \mathrm{SS}-\mathrm{AS}$ system at $25^{\bullet} \mathrm{C}$, including how to evaluate supersaturated states and nucleation rates within such a system, and (2) a description of the interaction of calcite $\{10 \overline{1} 4\}$ surfaces with manganese, based on the structural model proposed by Reeder (1996). As we will see, AFM observations of growth phenomena at a molecular scale can be explained as a result of the interaction of thermodynamic, kines, structural, and microtopographic factors.

\subsection{The Thermodynamics of the Mn-Ca- $\mathrm{CO}_{3}-\mathrm{H}_{2} \mathrm{O}$ SS-AS System and the Evaluation of Supersaturation and Nucleation Rates}

\subsubsection{Thermodynamic background}

In the Mn-Ca- $\bullet_{3}-\mathrm{H}_{2} \bullet \mathrm{SS}-\mathrm{AS}$ system at $25^{\bullet} \mathrm{C}$, a limited rhombohedral solid solution can be formed between the endmembers calcite $\left(\mathrm{CaC}_{3}\right)$ and rhodochrosite $\left(\mathrm{MnC}_{3}\right)$. In addition, there exists a double salt with the dolomite structure called kumahorite $\left(\mathrm{MnCa}\left(\mathrm{C}_{3}\right)_{2}\right)$. Although this SS-AS system seems to be simple, neither the extent and non-ideality of the solid solution nor the stability field for kumahorite have been unequivocally established. Several studies on natural and synthe $\mathrm{Mn}_{\mathrm{r}} \mathrm{Ca}_{1-\mathrm{x}} \mathrm{C}_{3}$ solid solution series have reported compositional ranges from total miscibility between endmembers (Goldschmidt and Graf, 1957; Fubini and Stone, 1983) to limited solid solubility with different ranges for miscibility gaps (Brand and Veizer, 1980; Ten Have and Heijnen, 1985). Furthermore, there is no agreement for the distribution coefficient values (Lorens, 1981; Mucci, 1988; Pingitore et al., 1988; Dromgoole and Walter, 1990; Böttcher, 1997), even though all the researchers found that, in comparison to $\mathrm{Ca}, \mathrm{Mn}$ is strongly incorporated into the calcite structure (i.e., $\mathrm{K}_{\alpha}>1$ ). Finally, the determination of the solubility product for the endmember rhodochrosite, $\mathrm{K}_{\mathrm{MnCO}_{3}}$, seems to be problematic, and a number of values for this parameter can be found in the literature. Some of the $\mathrm{K}_{\mathrm{MnCO}_{3}}$ values reported are: $10^{-10.99}$ (Garrels et al., 1960); $10^{-1062}$ (Wagman et al., 1982); $10^{-10}$ ss (Jolnnson, 1982) and $10^{-9.43}$ (Mc Beath et al., 1998). It is clear that this lack of agreement with respect to the precipitation behaviour in the Mn-Ca- $\mathbf{C}_{3}-\mathrm{H}_{2} \bullet$ SS-AS system makes it difficult to propose a consistent thermodynamic model. However, McBeath et al. (1998) have recently published new experimental data for the $\mathrm{Mr}_{\mathrm{C}} \mathrm{Ca}_{1-\mathrm{x}} \mathrm{C} \mathbf{Q}_{3}$ solid solution, obtained using electrochemical cells. These data allowe them to derive the excess Gibbs energy as a function of composition, $\Delta_{f} G_{M_{n_{1}} \mathrm{C}_{\boldsymbol{a}_{-1},} \mathrm{C}}$. Moreover, the authors provide an empirical expression for the solubility product of the $\mathrm{Mn}_{\mathrm{x}} \mathrm{Ca}_{1-\mathrm{x}} \mathrm{C}_{3}$ solid solution:

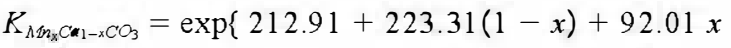

$$
\begin{aligned}
& \left.+0.40339\left(\Delta, G_{M n_{x} \mathrm{Cm}_{1-x} \mathrm{CO}_{3}}^{\mathbf{1}} / \mathrm{kJ} \mathrm{mol}^{-1}\right)\right\}
\end{aligned}
$$

where $\mathrm{x}$ is the mole fraction of $\mathrm{MnC}_{3}$ in the solid solution. This equation can be used to evaluate the supersaturation states in the $\mathrm{Mn}-\mathrm{Ca}-\mathrm{C}_{3}-\mathrm{H}_{2}-\mathrm{SS}-\mathrm{AS}$ system at $25^{\circ} \mathrm{C}$. Figure 1 shows the variation of the solubility product for $\mathrm{Mn}_{\mathrm{x}} \mathrm{Ca}_{1-\mathrm{x}} \mathrm{C}_{3}$ as a function of the composition. It is worth noting that for intermediate solid compositions $\left(X_{M_{n C} \bullet_{3}} \approx 0.5\right)$ the solubility exhibits a relative minimum.

\subsubsection{Supersaturation evaluation}

Supersaturation in SS-AS systems cannot be described by a single value but by a function of both solid and fluid composition. For the Mn-Ca-C $\boldsymbol{C}_{3}-\mathrm{H}_{2} \bullet \mathrm{SS}-\mathrm{AS}$ system, the function $\boldsymbol{\beta}(x)$ that expresses the supersaturation of aqueous solutions with respect to solid solutions has the following form (e.g., Prieto et al., 1993; Pumis et al., 1995):

$$
\boldsymbol{\beta}(x)=\frac{\boldsymbol{a}\left(\mathrm{Mn}^{2+}\right)^{\pi} \boldsymbol{a}\left(\mathrm{Ca}^{2+}\right)^{1-x} \boldsymbol{a}\left(\mathrm{CO}_{3}\right)}{K_{M n_{x} \mathrm{C} \mathrm{n}_{-x} \mathrm{CO}}}
$$

where $\boldsymbol{a}\left(\mathrm{Mn}^{2+}\right), \boldsymbol{a}\left(\mathrm{Ca}^{2+}\right)$, and $\boldsymbol{a}\left(\mathrm{CO}_{3}^{2-}\right)$ are the activities of the ions in the solution and $K_{\mathrm{Mn}_{\mathrm{x}} \mathrm{C}_{\mathbf{a}_{3}-\mathrm{C}} \mathrm{C}} \boldsymbol{C}_{3}$ is the solubility product as a function of the solid solution composition (E (1)). Figure 2a shows, for example, the supersaturation distribution as a funcwon of the solid composition for an aqueous solution with activities: $\boldsymbol{a}\left(\mathrm{Mn}^{2+}\right)=0.01 ; \boldsymbol{a}\left(\mathrm{C}^{2+}\right)=\boldsymbol{a}\left(\mathrm{CO}_{3}{ }^{2+}\right)=0.1$. As can be seen, the supersaturation maximum is reached for a solid composition with molar fraction $X_{M n C} \approx 0.5$, even though the $\mathrm{Ca}$ activity in the aqueous solution is 10 times higher than the Mn activity. This is a consequence of the particular shape of the solubility product function (E. (1)). Other compositions of the aqueous solution will result in supersaturation functions with maxima located at different solid solution compositions

\subsubsection{Nucleation rates}

Once the supersaturation function of an aqueous solution with respect to a solid solution is known, it is possible to evaluate the nucleation kinetics for each composition of the solid. This can be done by means of the nucleation rate function, $J(x)$, which is obtained by considering some of the basic parameters of the classical nucleation rate equation as functions of the solid composition (see references in Pina et al., 2000):

$$
J(x)=\Gamma(x) \cdot \exp \left[\frac{-B \cdot \xi \cdot \sigma^{3}(x) \cdot \Omega^{2}(x)}{k^{3} \cdot T^{3} \cdot(\ln S(x))^{2}}\right]
$$

where, $S(x)=\sqrt{\boldsymbol{\beta}(x)} ; o(\mathrm{x})$ is the interfacial free energy fumcino; $\Omega(x)$ is the molecular volume as a function of solid composition, and $\Gamma(x)$ is the preexponential factor as a function of solid composition (which involves a volume diffusion step and is dependent on the interfacial free energy and solubility). The other parameters in E (3) are: $k$, the Bolt mann constant; $T$, the absolute temperature; $B$, a geometrical factor, which is $2 \pi / 3$ for a spherical nucleus. Finally, $\xi$ is a correction factor $(0$ $<\xi<1$ ) related to the formation of heterogeneous nuclei (i.e., $J(x)$, expresse as nuclei per unit of area and unit of time). Such a parameter can be adjusted by considering experimental nucleation densities (e.g., obtained from AFM experiments). Although absolute values for nucleation rates given by E. (3) are not very reliable (the function is very sensitive to small variathons of the parameters in the equation), the $J(x)$ function is useful to determine the solid solution compositions that are kinetically favoured (Pina et al., 2000; Pina and Pumis, 2002). Figure $2 \mathrm{~b}$ shows the nucleation rate function corresponding to 


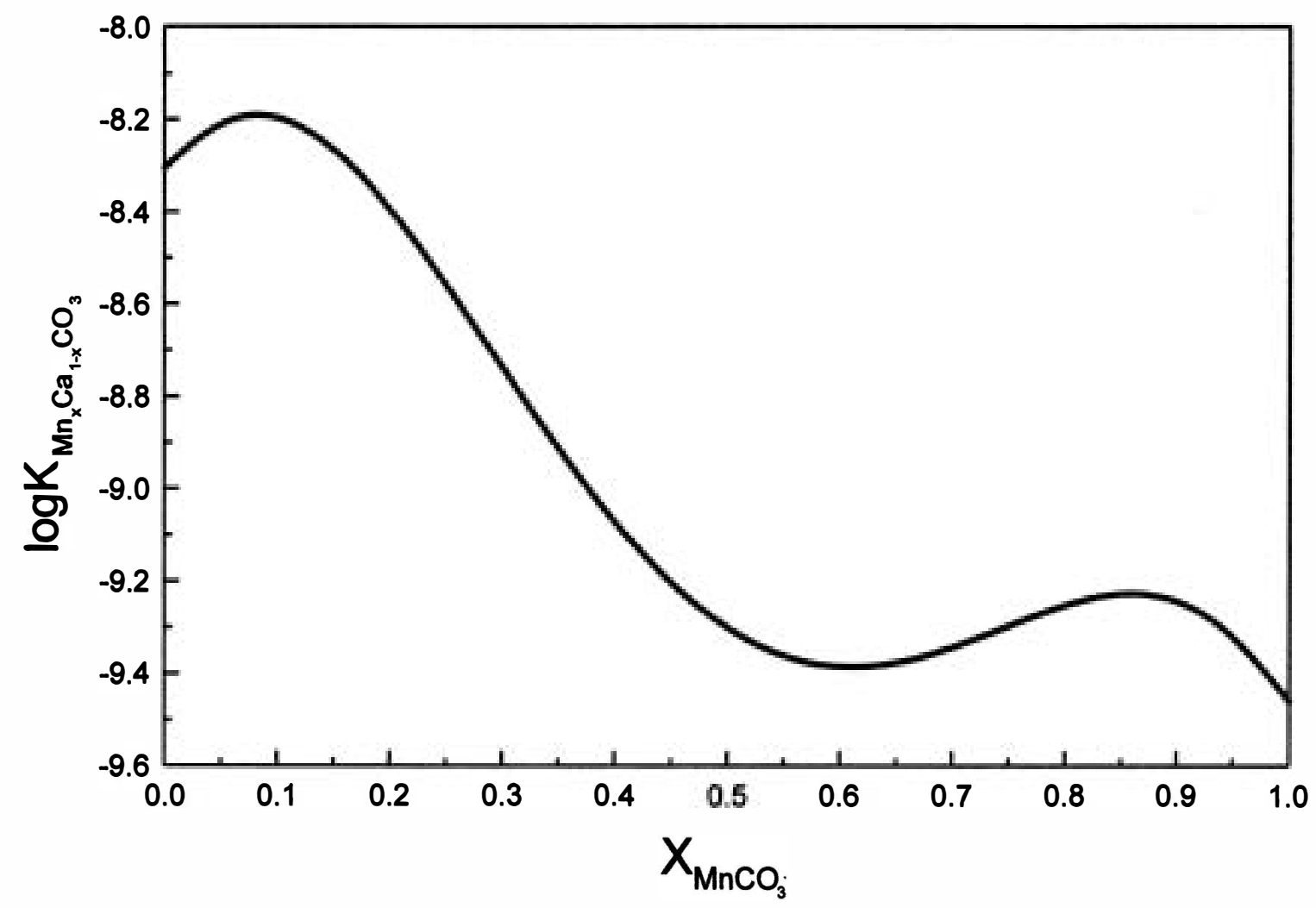

Fig. 1. Variation of the solubility product for $\mathrm{Mn}_{\mathrm{x}} \mathrm{Ca}_{1-\mathrm{x}} \mathrm{CO}_{3}$ as a function of the composition. The solubility exhibits a relative minimum for intermediate solid compositions $\left(\mathrm{X}_{\mathrm{MnC}_{3}} \approx 0.5\right)$.

the supersaturation distribution shown in Figure 2a. The endmember parameters required to calculate the $J(x)$ functions were taken from the literature. They are: $\sigma_{\text {calcite }}=97 \mathrm{~mJ} / \mathrm{m}^{2}$ and $\sigma_{\text {rhodochrosite }}=81 \mathrm{~mJ} / \mathrm{m}^{2}$ (Söhnel, 1982; Wu and Nancollas, 1999). The calculated molecular volumes are $\Omega_{\text {calcite }}=6.1$. $\times 10^{-29} \mathrm{~m}^{3}$ and $\Omega_{\text {rhodocrhosite }}=5.16 . \times 10^{-29} \mathrm{~m}^{3}$. Preexponential factors of the equation were estimated using the approximation: $\Gamma(x)=D / \Omega^{5 / 3}(x)$, where $\mathrm{D} \cong 10^{-9} \mathrm{~m}^{2} \mathrm{~s}^{-1}$ is the mean diffusion coefficient for ions in water.

\subsection{Structure of the Calcite $\{10 \overline{1} 4\}$ Surface, Mn Uptake and Adsorption Processes}

Since crystal growth takes place at the solid-aqueous interface, a comprehensive study of growth processes requires not only a macroscopic thermodynamic model but also a knowledge of crystal structure and surface microtopography of the growing phase. The interrelationships between such parameters and the anisotropic growth observed on calcite $\{10 \overline{1} 4\}$ surfaces (Reeder, 1996; Astilleros et al., 2000) can be elegantly established by means of the periodic bond (PBC) chain model of Hartman and Perdok (1955). The $\mathrm{PBCs}$ are defined as continuous connections through the structure by strong bonds. Because such bonds have the highest attachment energies, they play an important role in determining surface microtopography and growth anisotropy. Calcite $\{10 \overline{1} 4\}$ faces, which define the calcite cleavage rhombohedron, contain three non-equivalent PBCs parallel to the $\langle\overline{4} 41\rangle,\langle 2 \overline{2} 1\rangle$, and $\langle 010\rangle$ directions and, therefore, are flat $(F)$ faces (Heijnen, 1985). Steps parallel to a given set of PBCs are structurally identical, but because of the orientation of such steps to the symmetry elements, opposite directions of advancement for a given step are not equivalent $\left([\overline{4} 41]_{+},[48 \overline{1}]_{+}\right.$and $[\overline{4} 41]_{-},[48 \overline{1}]_{-}$, according to the notation used by Staudt and Reeder, 1994). Figure 3 shows a representative example of etch pit development on a calcite $\{10 \overline{1} 4\}$ surface in contact with water. Etch pits show a typical rhombohedral shape defined by [ $\overline{4} 41]$ and

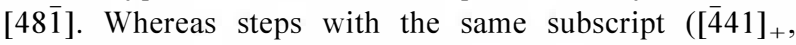
$[48 \overline{1}]_{+}$or $[\overline{4} 41]_{-},[48 \overline{1}]_{-}$, according to the notation used by Staudt and Reeder, 1994) are symmetrically related by means of a $c$-glide, no symmetry operation relates the $[\overline{4} 41]_{+}$or $[48 \overline{1}]_{+}$steps to either $[\overline{4} 41]_{-}$or $[48 \overline{1}]_{-}$steps, respectively. This non-equivalence of growth steps, which also determines growth and dissolution rates (positive steps migrate faster than negative steps; Hillner et al., 1992), is considered by Paquette and Reeder $(1990,1995)$ and Staudt and Reeder (1994) as the main reason for differential incorporation of trace elements into the calcite structure. In the model proposed by these investigators, two general types of kinks along $<\overline{4} 41>$ steps can be distinguished: the more constrained and smaller sites, distributed along [4 441$]_{-}$, [481] _ steps, and the less constrained and larger ones, which are present in the $[\overline{4} 41]_{+},[48 \overline{1}]_{+}$steps. Cations smaller than $\mathrm{Ca}(\mathrm{Mn}, \mathrm{Mg}, \mathrm{Co}, \mathrm{Cd})$ will tend to be incorporated in nega- 

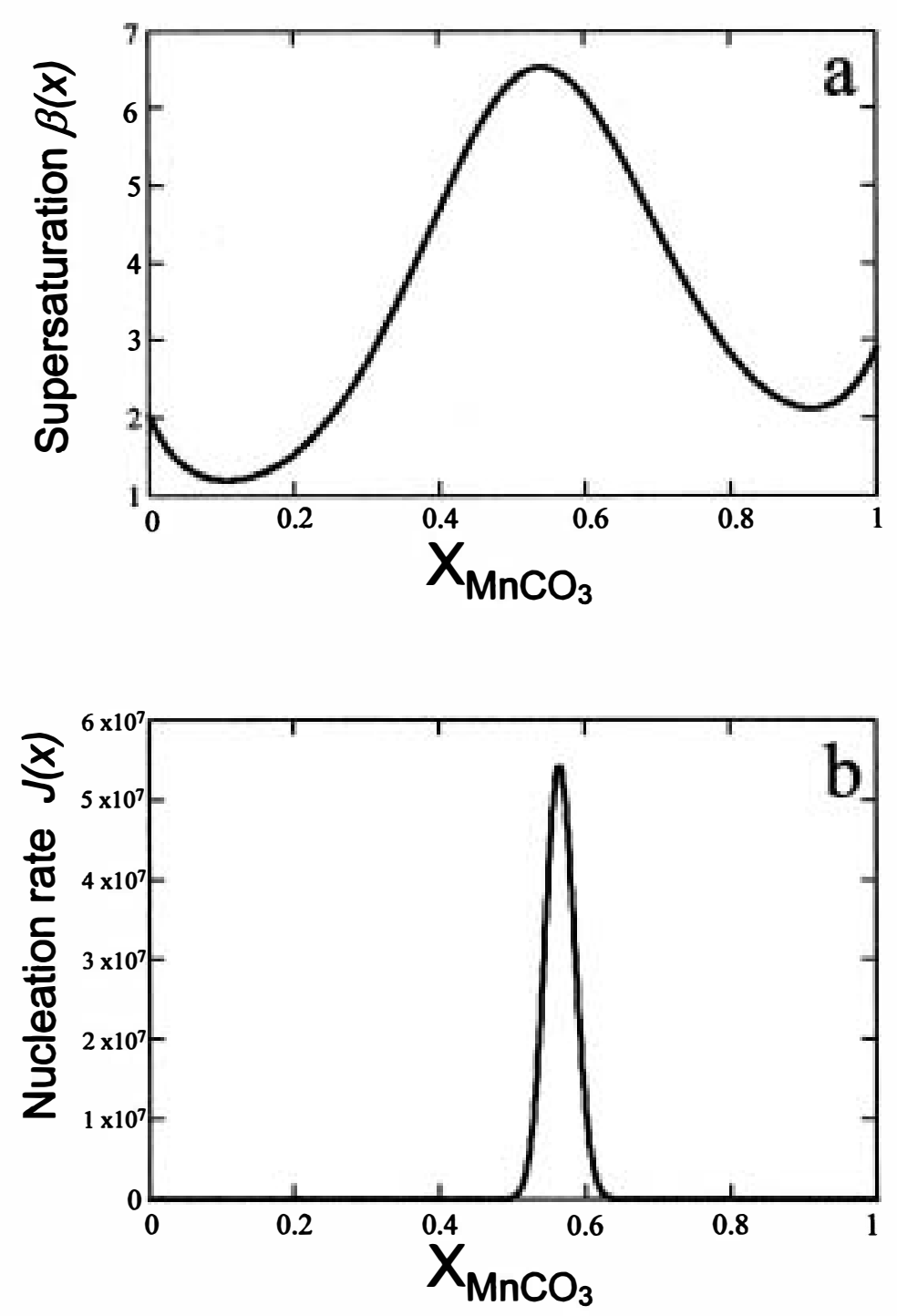

Fig. 2. (a) Supersaturation function, $\beta(x)$, and (b) nucleation rate function, $J(x)$, expressed in nuclei/ $\mu \mathrm{m}^{2} \cdot \mathrm{s}$ for a hypothetical aqueous solution with activities $\mathrm{a}\left(\mathrm{Mn}^{2+}\right)=0.01 ; \mathrm{a}\left(\mathrm{Ca}^{2+}\right)=\mathrm{a}\left(\mathrm{CO}_{3}^{2-}\right)=0.1$.

tive steps, whereas cations larger than $\mathrm{Ca}(\mathrm{Ba}, \mathrm{Sr})$ will be preferentially incorporated in positive steps.

The ionic radius of $\mathrm{Mn}^{2+}$ is $0.80 \AA$, considerably smaller than $\mathrm{Ca}^{2+}(0.99 \AA)$. This difference will result in a preferential incorporation of $\mathrm{Mn}^{2+}$ in the smaller sites located along negative steps and, probably, a lower detachment probability. Therefore, faster step advancement in comparison to pure calcite can be expected. However, the simultaneous incorporation of $\mathrm{Mn}$ and $\mathrm{Ca}$ into the calcite structure, particularly at high growth rates, will have an important effect on the distribution of defects.

\section{MATERIAL AND METHODS}

Crystal growth experiments were carried out at $25^{\circ} \mathrm{C}$ in situ in a fluid cell of a Digital Instruments Multimode Atomic Force Microscope working in contact mode. Care was taken to ensure that the tip did not affect the surface during the scan. Repeated scans of the tip over the same area did not cause any appreciable differences at this location relative to the rest of the image. Before each growth experiment, deionised water was passed over the crystal to clean the cleaved $\{10 \overline{1} 4\}$ calcite, as well as to adjust the AFM parameters. Calcite samples used as substrates were cleaved from a block of optically clear Iceland Spar. $\mathrm{Ca}^{2+}-\mathrm{Mn}^{2+}-\mathrm{CO}_{3}^{2-}$ aqueous solutions were prepared by mixing $\mathrm{Na}_{2} \mathrm{CO}_{3}, \mathrm{MnCl}_{2}$, and $\mathrm{CaCl}_{2}$ aqueous solutions (SIGMA $99+\%)$. The $\mathrm{pH}$ of the solutions was measured using a TESTO $230 \mathrm{pH}$ meter. A value of $10.20 \pm 0.05$ was obtained in all cases. The $\mathrm{pH}$ meter electrode (type $05 \mathrm{pH}$ ) was calibrated using 7.00 and 10.00 buffers (Shott Geräte). Table 1 shows the composition of the solutions used in the growth experiments. Solutions were prepared immediately before injection in the fluid cell to avoid the precipitation of $\mathrm{MnO}_{2(\mathrm{~s})}$.

Supersaturation states of the solutions were evaluated using Eq. (2). For this purpose, it is necessary to calculate the 


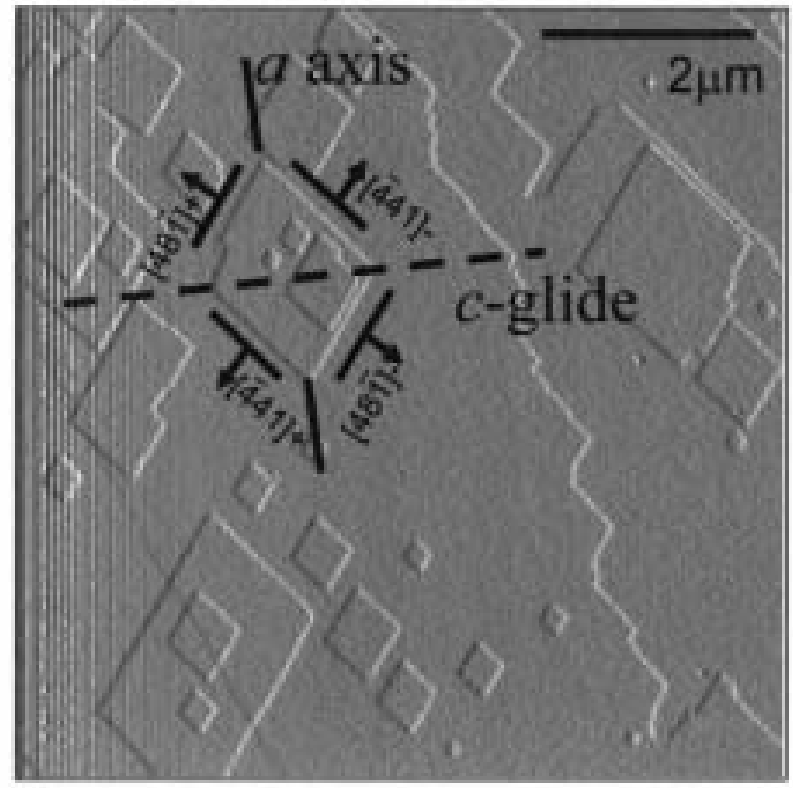

Fig. 3. AFM image of a calcite $\{10 \overline{1} 4\}$ surface in water. On the dissolution pit, four non-equivalent $\langle\overline{4} 41>+$ and $<\overline{4} 41>-$ steps, as well as the a-axis and c-glide trace are indicated.

activitives of the ions in solution. The activity coefficients for $\mathrm{Ca}^{2+}, \mathrm{Mn}^{2+}$, and $\mathrm{CO}_{3}^{2-}$ were computed using the extended Debye-Hückel formula (Sturmm and Morgan, 1981). The aqueous speciation program used considered the following species: $\mathrm{H}^{+}, \mathbf{\bullet H}^{-}, \mathrm{Ca}^{2+}, \mathrm{Mn}^{2+}, \mathrm{C}_{3}^{2-}, \mathrm{Cl}{ }^{-}, \mathrm{Na}^{+}, \mathrm{HC}_{3}{ }^{-}, \mathrm{H}_{2} \mathrm{C}_{3}{ }^{0}$, $\mathrm{Ca} \mathrm{H}^{+}, \mathrm{CaC}_{3}{ }^{0}, \mathrm{CaHC}_{3}{ }^{+}, \mathrm{Mn} \bullet^{+}, \mathrm{MnC}_{3}{ }^{0}, \mathrm{MnHC}_{3}{ }^{+}$, $\mathrm{NaCl}^{0}, \mathrm{Na}^{0}{ }^{0}, \mathrm{NaC}_{3}{ }^{-}, \mathrm{Na}_{2} \mathrm{C}_{3}{ }^{0}$, and $\mathrm{NaHC}_{3}{ }^{0}$. Ion-size parameters require to apply the extended Debye-Hückel formula were taken from Truesdel and Jones (1974). Table 1 (last colunin) shows the calculated ionic strength for the solutions. The ionic strength values $(\mathrm{I}<0.0134)$ are within the range of applicability of the extended Debye-Hückel formula. As an example of calculated solution compositions, Table 2 shows free ion and ion pair concentrations in experiment number three. Note that the calculated $\mathrm{pH}$ value is very similar to our electromeric measurements. This is a test of the applicability of the speciation model used.

For all solutions used in the experiments, the supersaturation with respect to the endmember calcite was constant. The supersaturation with respect to rhodochrosite was increased in each experiment by increasing the concentration of $\mathrm{Mn}$. To maintain a constant supersaturation value with respect to calcite, the $\mathrm{Ca}$ concentrations in the solutions were adjusted. In all the experiments, the dissolved inorganic carbon concentration was maintained constant.

\section{AFM OBSERVATIONS}

As mentioned in the previous section, before each growth experiment, deionized water was injected in the fluid cell of the AFM. The calcite $\{10 \overline{1} 4\}$ surface in contact with water rapidly begins to dissolve by both step retreat and formation of etch pits. Etch pits on calcite usually show a typical rhombohedral shape defined by the [48 $\overline{1}]$ and [ $\overline{4} 41]$ steps, which dissolve at different velocities. Therefore, by direct observation of the development of such etch pits, it is possible to determine unequivocally the crystallographic directions on calcite $\{10 \overline{1} 4\}$ surfaces before each growth experiment.

Once the orientation of the calcite substrate was established, the $\mathrm{Ca}^{2+}-\mathrm{Mn}^{2+}-\mathrm{CO}_{3}^{2-}$ solutions described in Table 1 were injected into the fluid cell of the AFM. In all the experiments, growth on the surface was observed. Figure 4 shows a growth sequence on a calcite $\{10 \overline{1} 4\}$ surface using solution 1 . The first image (a) was taken immediately after flowing deionised water and a few seconds before injection of the growth solution. In successive images, step advancement occurs. At certain places, it is possible to observe a temporary stoppage of the step advancement. As a result, the initially straight step edges are distorted and become rounded, developing lobes during growth. Arrows 1 and 2 in Figure 4 indicate sites along the step edges where the growth slows down. A detailed observation of the sequence shows that such sites correspond to the previous corners of the etch pits. From these observations, a relationship between the original topography (arrows 1 and 2) and the lobed areas can be established.

When the concentration of $\mathrm{Mn}$ in the solution is slightly higher (solution 2), the growth behaviour is considerably modified. Figure 5 shows the evolution of the calcite $\{10 \overline{1} 4\}$ surface in contact with this solution. Although lateral step advancement is again the operating growth mechanism, only the first elementary growth layer advancing on the preexisting surface grows normally. This first newly formed substrate exerts a strong control on the subsequent surface evolution: when a second growth layer reaches previously grown areas, it abruptly reduces its velocity and growth stops. The growth is, however, normal on the original pure calcite surface. This inhomogeneous growth leads to an ahnost perfect reproduction of the topography of the original surface (cf. Fig. 5a with Fig. 5c). After some minutes, the stopped steps begin again to spread and edges become wavy (Fig. 5d). The velocity of step advancement is now considerably lower that in the former case. Figure 6 a shows the advancement of the $[\overline{4} 41]_{+}$steps over both the original surface and the newly grown elementary growth layer. As can be seen, the advancement is similar for steps growing from the three solutions on the original calcite surfaces. In contrast, step advancement on previously grown substrates is strongly retarded. As Figure $6 \mathrm{~b}$ shows, the step rates

Table 1. Concentrations of the solutions used in the AFM growth experiments.

\begin{tabular}{|c|c|c|c|c|c|}
\hline Solution $n^{\bullet}$ & $\begin{array}{c}{\left[\mathrm{CaCl}_{2}\right]} \\
(\mathrm{mmol} / \mathrm{L})\end{array}$ & $\begin{array}{c}{\left[\mathrm{MnCl}_{2}\right]} \\
(\mathrm{mmol} / \mathrm{L})\end{array}$ & $\begin{array}{l}{\left[\mathrm{Na}_{2} \mathrm{CO}_{3}\right]} \\
(\mathrm{mmol} / \mathrm{L})\end{array}$ & $X_{M n^{2}+\mathrm{aq}}$ & Ionic Strength \\
\hline 1 & 0,215 & 0,01 & 0,3 & 0.021 & $1,31 \times 10^{-3}$ \\
\hline 2 & 0,215 & 0,025 & 0,3 & 0.051 & $1,32 \times 10^{-3}$ \\
\hline 3 & 0,2 & $\bullet, 05$ & 0,3 & 0.096 & $1,34 \times 10^{-3}$ \\
\hline
\end{tabular}


are related to the Mn concentration in solution. For solution 3, step growth is completely inhibited during the observation time. However, the higher Mn concentration in solution 3 results in an important modification of growth behaviour: the ransition to a two-dimensional growth mechanism. This can be observed in Figure 7 where the formation of a number of two-dimensional nuclei on the surface occurs simultaneously with the step advancement. As growth proceeds, neighbouring nuclei come into contact and coalesce, forming a whole new layer after a short time. The growth sequence shows again the structural control of the calcite surface on the growth process. In this case, the effect is even more pronounced. The newly formed surface not only avoids the step advancement, but also prevents the formation of these two-dimensional nuclei on it. The dotted line in Figure $7 \mathrm{~b}$ indicates the original position of the step edge, and it separates a region where nucleation density is very high (left) from another region, generated during the growth experiment, where nuclei formation is inhibited. Such a phenomenon, together with the coalescence of nuclei, results in the reproduction of the preexisting microtopography. Once the coating of the preexisting surface has taken place, the growth process seems to freeze. However, at higher magnification, the formation of a second generation of tiny nuclei, different from the first ones, can be detected (Fig. 7d). Such nuclei are characteristic of growth on the newly formed surface, and form preferentially close to step edges. Figure 8 shows the two
Table 2. Calculated free ion and ion pairs molalities for the solution in experiment number 3 (Table 1 ).

\begin{tabular}{llll}
\hline $\begin{array}{c}\text { Free ions and } \\
\text { ion pairs }\end{array}$ & \multicolumn{1}{c}{ Molality } & $\begin{array}{c}\text { Free ions and } \\
\text { ion pairs }\end{array}$ & \multicolumn{1}{c}{ Molality } \\
\hline $\mathrm{H}^{+}$ & $6,56 \times 10^{-11}$ & $\mathrm{CaCO}_{3}^{\bullet}$ & $2,31 \times 10^{-5}$ \\
$\mathrm{OH}^{-}$ & $1,66 \times 10^{-4}$ & $\mathrm{CaHCO}_{3}^{+}$ & $2,31 \times 10^{-7}$ \\
$\mathrm{Ca}^{2+}$ & $1,96 \times 10^{-4}$ & $\mathrm{MnOH}^{+}$ & $7,35 \times 10^{-6}$ \\
$\mathrm{Mn}^{2+}$ & $2,07 \times 10^{-5}$ & $\mathrm{MnCO}_{3}^{\bullet}$ & $2,18 \times 10^{-5}$ \\
$\mathrm{CO}_{3}^{-}$ & $1,16 \times 10^{-4}$ & $\mathrm{MnHCO}_{3}^{+}$ & $1,53 \times 10^{-7}$ \\
$\mathrm{Cl}^{-}$ & $5,2 \times 10^{-4}$ & $\mathrm{NaCl}^{\bullet}$ & $7,17 \times 10^{-9}$ \\
$\mathrm{Na}^{+}$ & $5,99 \times 10^{-4}$ & $\mathrm{NaOH}^{\bullet}$ & $5,79 \times 10^{-\mathbf{8}}$ \\
$\mathrm{HCO}_{3}^{-}$ & $1,38 \times 10^{-4}$ & $\mathrm{NaCO}_{3}^{-}$ & $1,10 \times 10^{-6}$ \\
$\mathrm{H}_{2} \mathrm{CO}_{3}^{\bullet}$ & $1,88 \times 10^{-8}$ & $\mathrm{Na}_{2} \mathrm{CO}_{3}^{\bullet}$ & $1,53 \times 10^{-1}$ \\
$\mathrm{CaOH}^{+}$ & $5,53 \times 10^{-7}$ & $\mathrm{NaHCO}_{3}^{\bullet}$ & $4,28 \times 10^{-\mathbf{8}}$ \\
\hline
\end{tabular}

different types of small nuclei. The first type includes very small nuclei exhibiting a high nucleation density. They are invariably formed on the surface created by the advancement of slow steps (arrow 1). In contrast, the second type consists of nuclei that are comparatively bigger and scarcer. Their formaion preferentially occurs on the surface generated by the advancement of faster steps (arrow 2).

The growth behaviour described above exhibits a variety of phenomena that occur almost simultaneously: (1) a primary two-dimensional nucleation event, (2) stoppage of growth when they reach previously coated surfaces, and (3) a second-
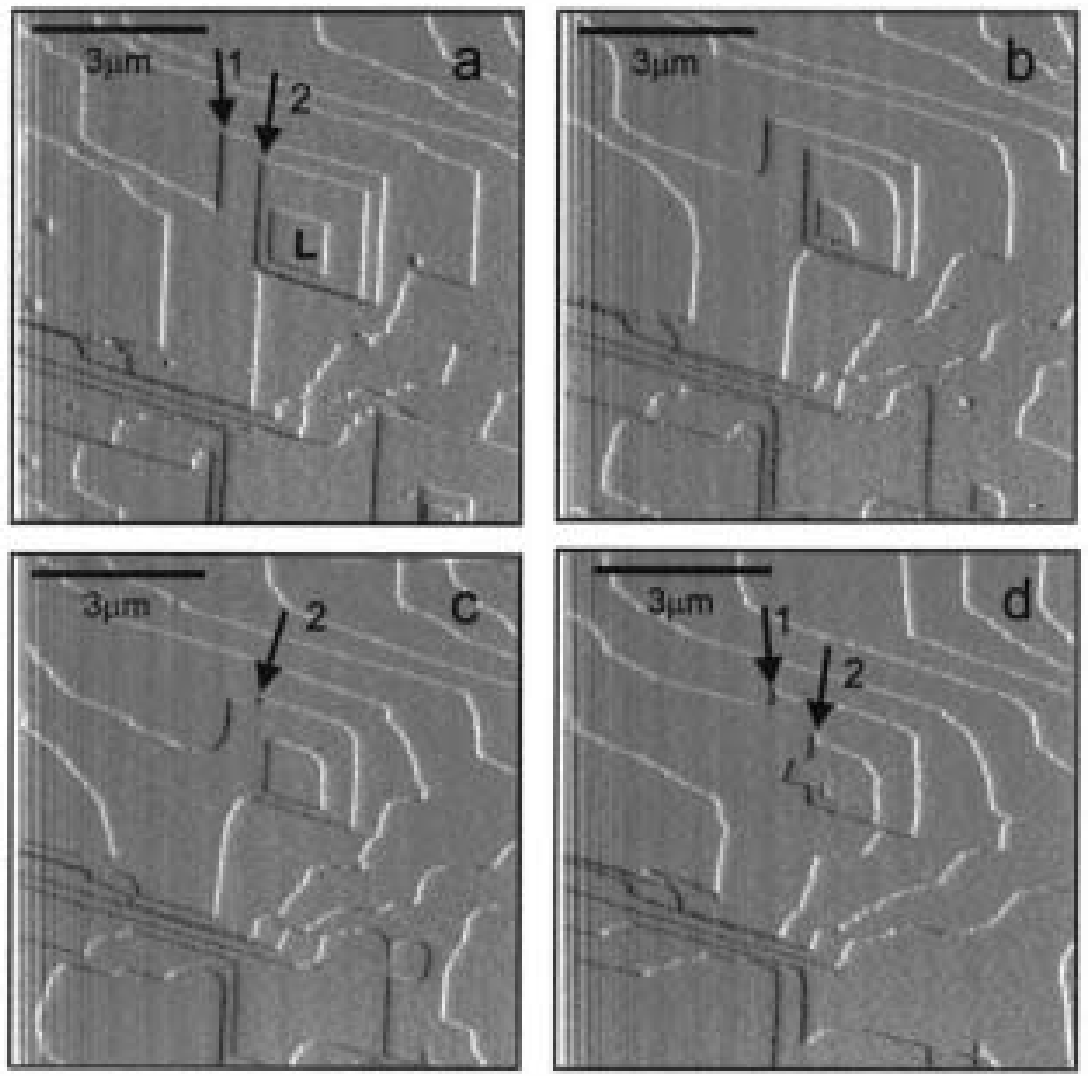

Fig. 4. Growth sequence on calcite $\{10 \overline{1} 4\}$ face from solution 1 (see Table 1). The surface "L" is the deepest, and the relative heights of other terraces can be deduced from the step contrast. Arrows indicate reference points. AFM images were taken at intervals of $\sim 1 \mathrm{~min}$. 

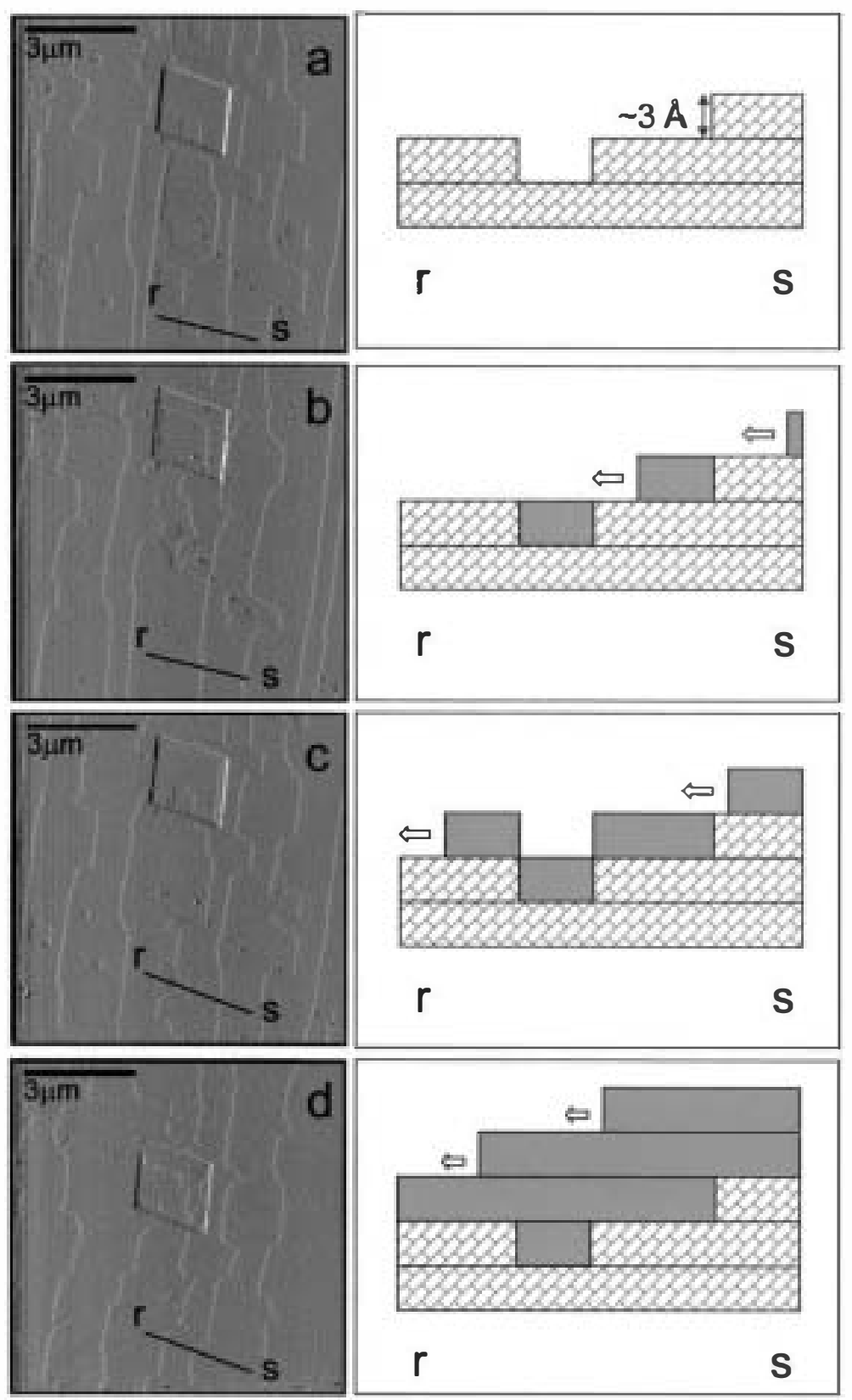

Fig. 5. (a-d) Growth sequence on calcite $\{10 \overline{1} 4\}$ face from solution 2 (see Table 2) showing the control of the surface on the growth process. The whole sequence of AFM images took $\sim 15 \mathrm{~min}$. The comparison of images (a) and (c) reveals the phenomenon of reproduction of the original surface microtopography. The schemes show the relations between original and newly-formed layers.

ary two-dimensional event close to step edges and showing differences in both nucleation density and nuclei size.

\section{DISCUSSION}

The AFM observations described above indicate that the growth behaviour of calcite $\{10 \overline{1} 4\}$ faces in the presence of $\mathrm{Mn}$ is a consequence of the interplay of thermodynamic, linetic, structural, and microtopographic factors. Therefore, we will discuss all the phenomena observed on the basis of the ideas presented in section 2 (above).
The most obvious phenomenon revealed by our experiments is the sansition from simple step advancement (solutions 1 and 2) to a two-dimensional nucleation growth mechanism (soluron 3). This can be explained by comparing the supersaturation distributions for the growth solutions. Figure 9a shows the supersaturation functions, $\boldsymbol{\beta}(x)$, calculated for solutions 1,2 , and 3 . As can be seen, these three solutions are supersaturated with respect to the whole range of $\mathrm{Mn}_{x} \mathrm{Ca}_{1-x} \mathrm{CO}_{3}$ solid solution compositions. However, while the supersaturation for pure calcite remains constant, the increase of $\mathrm{Mn}$ from solution 1 to 


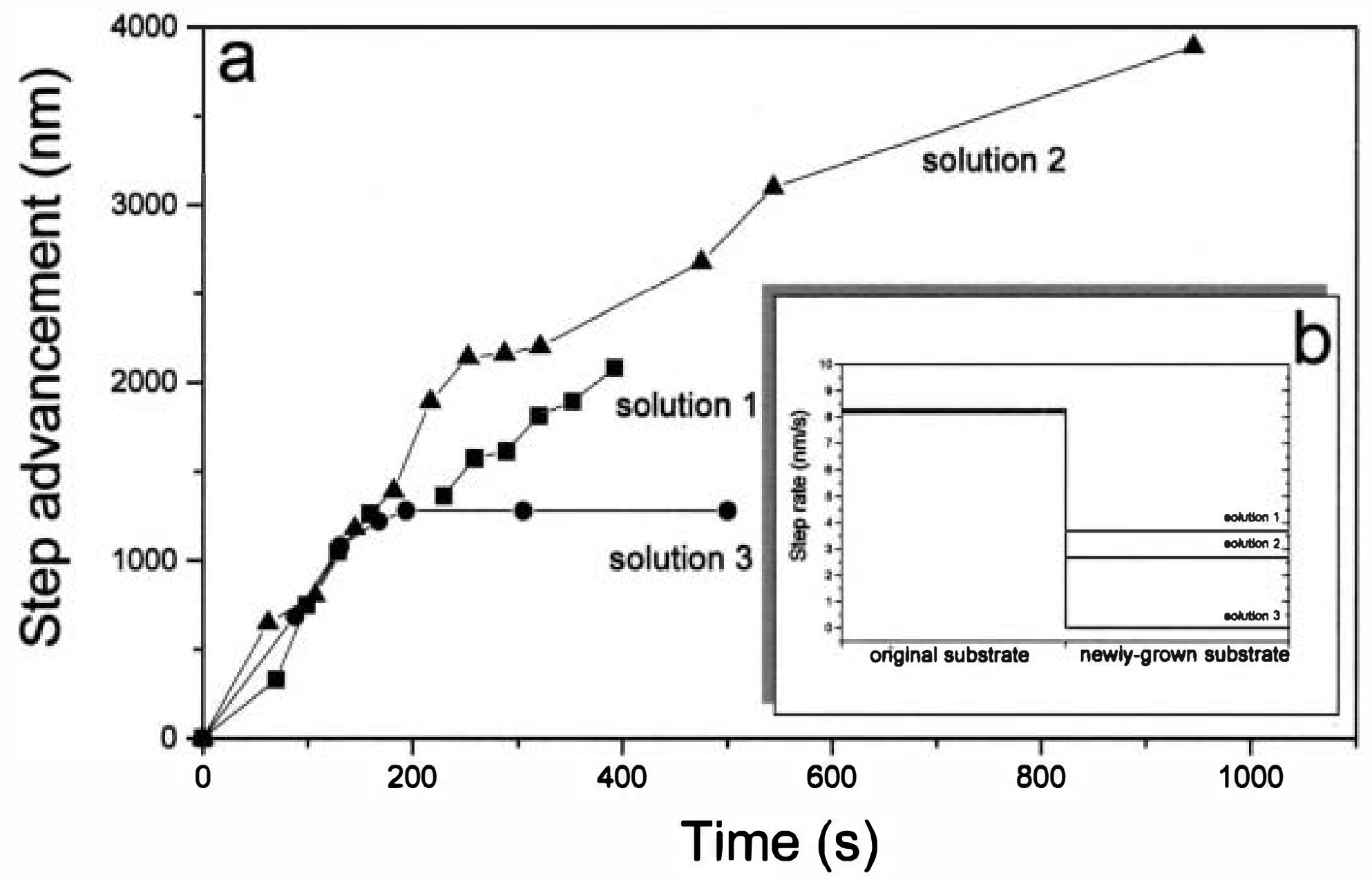

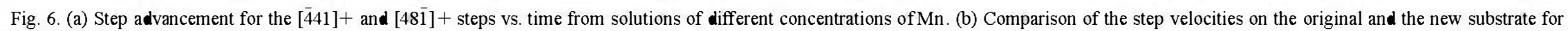
the three solutions used. 

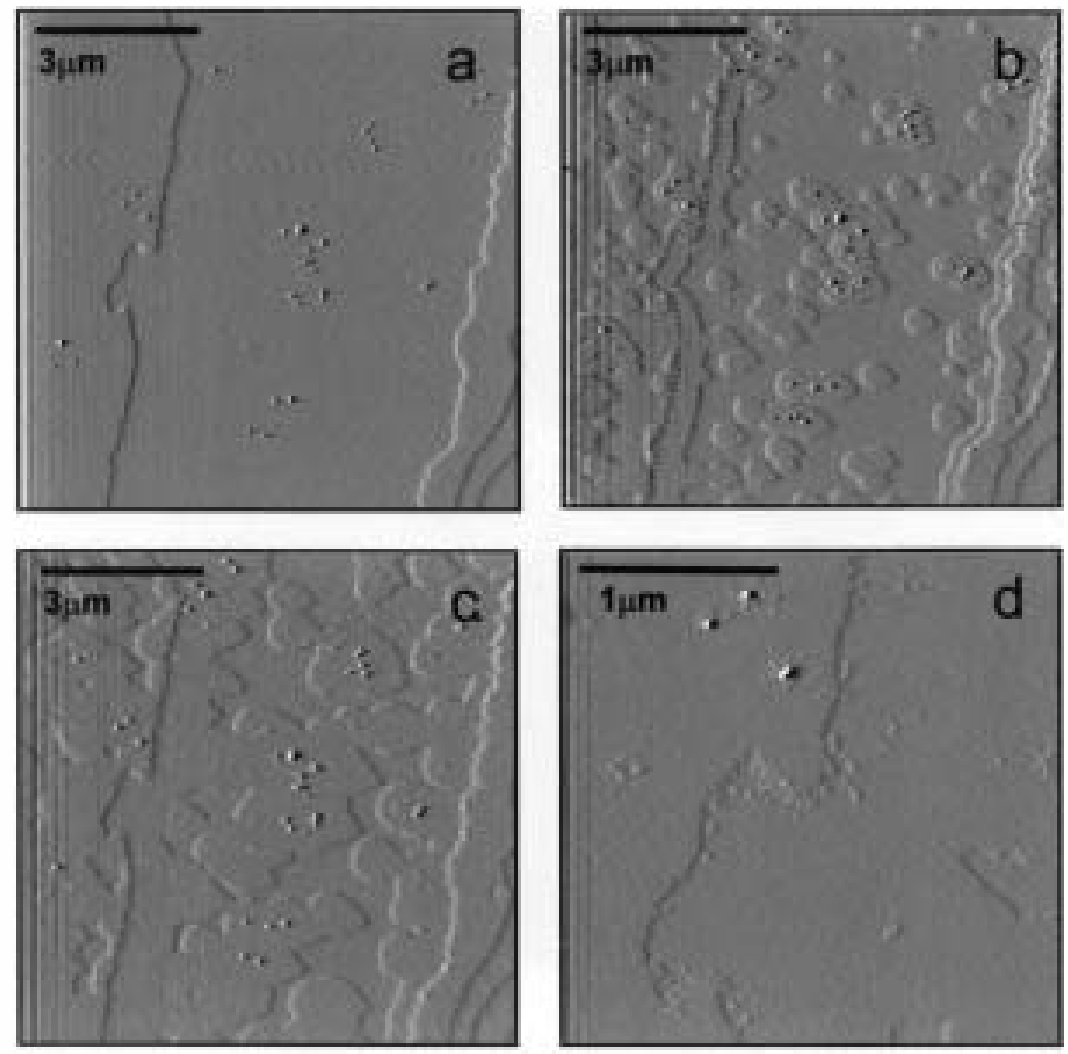

Fig. 7. Growth sequence on the calcite $\{104\}$ face from solution 3 (see Table 1). (a-c) Growth occurs by step advancement and two-dimensional nucleation mechanisms. (d) Once the surface is completely coated, a second twodimensional event close to the step edges can be observed. The AFM images were taken over $5 \mathrm{~min}$.

solution 3 leads to an increase in the supersaturation with respect to the rest of solid solution compositions. Since growth mechanisms operating on a surface depend on supersaturation (Sunagawa, 1987), by increasing the supersaturation, the ransitional supersaturation value, $\boldsymbol{\beta}^{*}$, which separates step advancement and two-dimensional nucleation growth mechanisms, will be exceeded. For the three solutions used, the maximum supersaturation corresponds to a solid composition with a mol faction $\mathrm{X}_{\mathrm{MnCO}_{3}} \approx 0.5$. Therefore, the ansitional supersaturation between growth mechanisms for a solid soluton $X_{M_{n} C_{3}}=0.5$ has to be placed somewhere between the maxima for curves 2 and 3 (point $\boldsymbol{\beta}_{M_{n} C \boldsymbol{\bullet}_{3}=\boldsymbol{\bullet} s}^{*}$ in Figure 9). In addition, AFM experiments conducted by Teng et al. (1997) have shown that the ransitional supersaturation for pure calcite
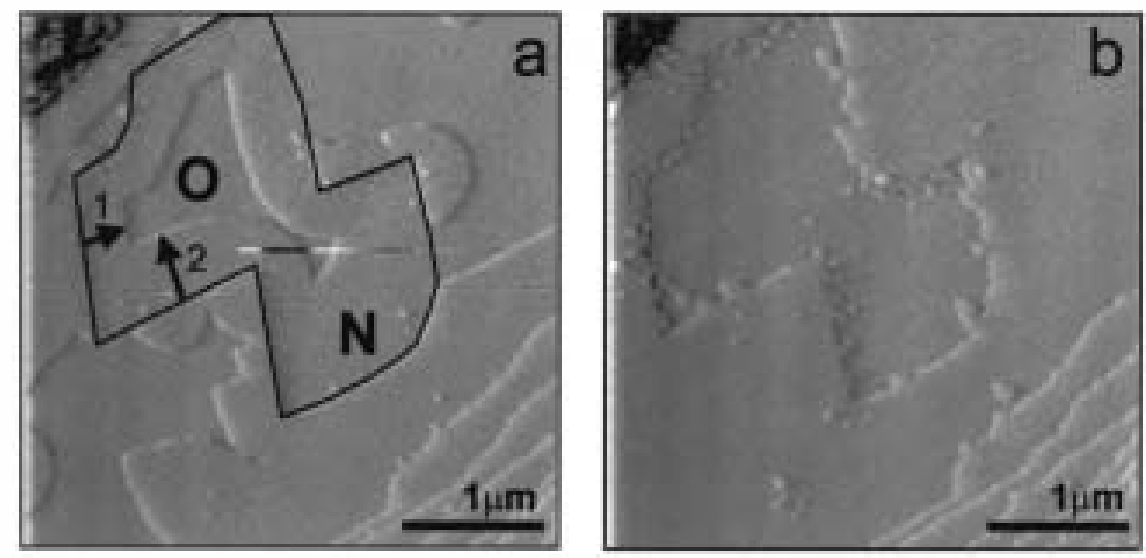

Fig. 8. (a) Closing of an etch pit from solution 3. The solid line indicates the original shape of the etch pit. "O" is the original calcite surface, and " $N$ " is the newly-grown layer. (b) Formation of a second generation of nuclei (see description in text). 

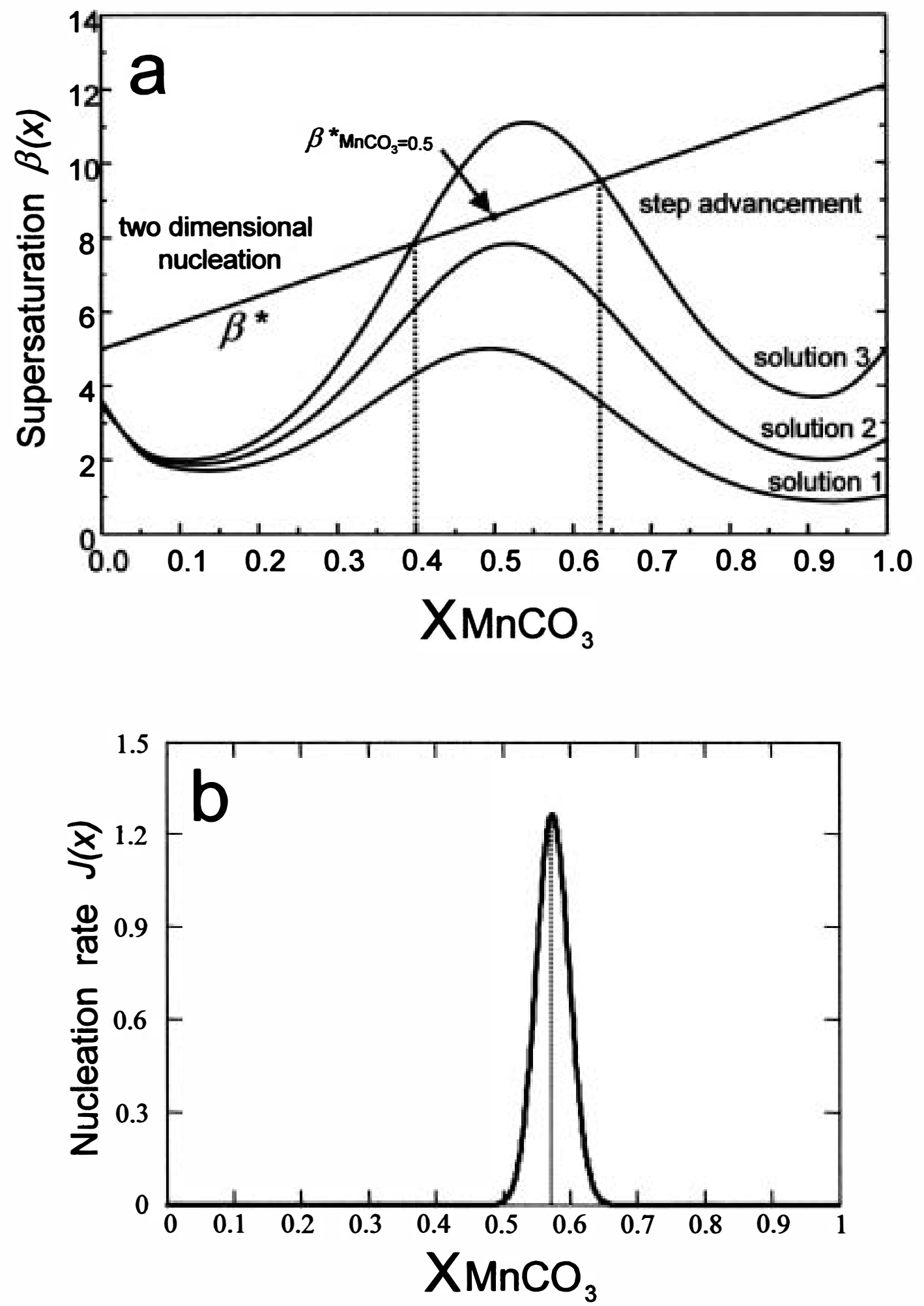

Fig. 9. (a) Supersaturation functions, $\beta(x)$, for solutions 1,2 , and 3 calculated using Eq. 2 . The $\beta^{*}$ line represents the variation of the transitional supersaturation between step advancement and two-dimensional nucleation as a function of the solid composition. The dotted lines show the solid compositions for which the two-dimensional nucleation is the only possible growth mechanism (solution 3). (b) Nucleation rate function, $J(x)$, expressed in nuclei $/ \mu \mathrm{m}^{2} \cdot \mathrm{s}$ for solution 3 . The basic parameters introduced in Eqn. 3 were taken from the literature (see text), and the correction factor for heterogeneous nucleation, $\xi$, was adjusted considering the nucleation densities observed in the AFM experiments. The maximum of such a function gives the most kinetically favoured solid solution composition. 
$\{10 \overline{1} 4\}$ faces is $\boldsymbol{\beta}_{M n C}^{*} \bullet_{3}=\bullet=5$. If we assume a linear variation of the ransitional supersaturation as a fumction of the solid solution composition (Pina et al., 2000), then a line from $\boldsymbol{\beta}_{M n C \bullet_{3}=\bullet}^{*}(\boldsymbol{\beta}=5)$ through the region where $X_{M n C \bullet_{3}}=0.5$ that passes between curves 2 and 3 would give the ransitional supersaturation for the pure endmember rhodochrosite $\boldsymbol{\beta}_{M n C \bullet_{3}=1}^{*} \approx 12$. Given the fact that rhodochrosite is less soluble than calcite (Fig. 1), such a value is reasonable.

From inspection of Figure 9a, it is clear that only solid solution compositions, whose supersaturation are projected above the $\boldsymbol{\beta} *$ line, can grow according to a two-dimensional nucleation growth mechanism from solution 3 . This allows us to propose the $0.4<X_{M_{n} \bullet_{3}}<0.65$ compositional range for the nuclei formed on calcite $\{10 \overline{1} 4\}$ surfaces. However, the $\boldsymbol{\beta}(x)$ function does not provide information about the nucleation kinetics. The calculation of the nucleation rate function, $J(x)$, allows us to estimate the kinetically most favourable composithon for the nuclei. Figure $9 \mathrm{~b}$ shows the distribution of nucleation rate as a fumction of the solid composition for solution 3 . As can be observed, in this case, the maximum does correspond to the maximum of supersaturation and the most probable composition of the nuclei will be $X_{M_{n} C_{3}} \approx 0.57$. This value is in agreement with experimental data published by other authors (Dromgoole and Walter, 1990; Böttcher, 1993) for solutions with molar fractions similar to our solution 3 (see Table 1). Our calculations are also in good agreement with the compositions reported by Fernández-González and Prieto (2000) for $\mathrm{Mn}_{\mathrm{z}} \mathrm{Ca}_{1-\mathrm{x}} \mathrm{CO}_{3}$ crystals grown in a gel medium at high supersaturations. These authors obtained crystals with molar fracions in the range of $0.45<X_{M_{n C} \bullet_{3}}<0.60$ when they used aqueous solutions with molar fractions $0.05<\mathrm{Y}_{\mathrm{Mn}^{2+} \text {, } q}<0.2$.

Note that we do not assume equilibrium compositions for the precipitates. On the contrary, the composition will be determined by the nucleation kinetics, i.e., the value of the nucleation rate for the different solid solution compositions. The most probable composition will be that for which nucleation rate is maximum. Moreover, our considerations are independent of the $\mathrm{K}_{\mathrm{MnCO}_{3}}$ chosen. Note that we calculated the supersaturation function using $\mathrm{K}_{\mathrm{MnCO}_{3}}=10^{-9.43}$ (McBeath et al., 1998). This is the highest value proposed for $\mathrm{K}_{\mathrm{MnCO}_{3}}$ by different authors (see section 2.1.1 above). Calculation of supersaturation using any other value for $\mathrm{K}_{\mathrm{MnCO}_{3}}$ would lead to higher $\boldsymbol{\beta}(x)$ distributions. In such a case, the range of possible compositions for the precipitate would be wider. However, our main arguments would still be valid.

Although the characteristics of supersaturation and nucleation rate fumctions provide a general view of the growth process, our AFM observations clearly reveal that the actual growth behaviour is strongly controlled by the interaction between the calcite $\{10 \overline{1} 4\}$ surface stucture and the supersaturated solutions. Such a control has as the most obvious effect the inhibition by first-grown layers on subsequent step advancement, which results in the reproduction of the preexisting topography. This is directly related to the Mn concentration in the aqueous solution. The higher Mn concentration in solution (and, therefore, the higher incorporation in growing steps), the more exact is the reproduction of the preexisting topography. Thus, an explanation of such an effect must be found in the differences in chemistry and surface properties of pure calcite and the newly formed $\mathrm{Mn}_{\mathrm{x}} \mathrm{Ca}_{1-\mathrm{x}} \mathrm{CO}_{3}$ layers. Because of the differences in ionic radii between $\mathrm{Ca}^{2+}(0.99 \AA)$ and $\mathrm{Mn}^{2+}$ $(0.80 \AA)$, the incorporation of a significant amount of $\mathrm{Mn}$ in the growing calcite steps can produce distorions around the $\mathrm{Mn}$ and $\mathrm{Ca}$ atoms. As a result, the terrace surface becomes crumpled and irregular and, on average, the latice parameters are reduced, causing a decrease of step height. Both (the difference in height and the formation of irregular terraces, which will be more important for larger substitutions of $\mathrm{Ca}$ by $\mathrm{Mn}$ ), are the first barriers to the advancement of the growing step on the new-formed surface. In addition, as we mentioned above, the increase in Mn concentration of the aqueous solutions implies an increase in supersaturation and, consequently, an increase in both growth rates and $\mathrm{Mn}$ incorporation. The formation of Mn-rich calcites at high supersaturations seems to be associated with poorly organised and defective surfaces. This has been demonstrated by the diffuseness of X-ray pattems (Goldsmith and Graf, 1957) that can be related to random inclusions of water molecules in the structure (Lippmann, 1973) and by the observation of crystals with rounded and rough faces (Femández-González and Prieto, 1999). Evidence of the accumulation of defects on calcite $\{10 \overline{1} 4\}$ surfaces containing Mn was obtained by passing deionised water over a surface after growth from an $\mathrm{Mn}^{2+}-\mathrm{Ca}^{2+}-\mathrm{CO}_{3}{ }^{2-}$ solution (solution 1). As can be observed in Figure 10, dissolution proceeds quickly by developing a high density of small etch pits on those areas where $\mathrm{Mn}_{\mathrm{x}} \mathrm{Ca}_{1-\mathrm{x}} \mathrm{CO}_{3}$ layers were previously formed. This is clearly indicative of the presence of a high number of point defects (Sangwal, 1987). Finally, Mn and Ca have a different physicochemical behaviour (e.g., hydration and absorption energies), and this will be reflected in differences in surface speciation (Van Cappellen et al., 1993). All these factors can be sufficient to prevent, at least momentarily, the advancement of the growth step on the newly formed Mn-bearing substrate, resulting in the reproduction of the microtopographic features of the original surface.

In situ AFM observations have also shown that the new substrate affects not only the step advancement, but also the formation of two-dimensional nuclei (solution 3). On the newly grown surfaces, nuclei are scarcer and smaller than those previously grown on pure calcite $\{10 \overline{1} 4\}$ surfaces. In addition, as we described in section 4 (above), the second generation of nuclei are of two types: (1) small and with high nucleation density on the slow-growth steps and (2) bigger and with low nucleation density on the fast-growth steps. This heterogeneous distribution of nuclei is consistent with the specific incorporaion behaviour expected for the $\mathrm{Mn}$ in the calcite model by Reeder (1996). The steps with lower velocities (denoted by -) correspond to those steps presenting an acute angle (close kink site), where the incorporation of $\mathrm{Mn}$ is preferred. A higher $\mathrm{Mn}$ content in these areas promotes the formation of a high number of small nuclei. In contrast, on the surfaces generated by the + steps, where the Mn content is presumably lower, nuclei have a low nucleation density and they reach a larger size.

The phenomena described and discussed in this paper demonstrate the complexity of the surface processes, which can be observed when the $\mathrm{Mrn}_{\mathrm{x}} \mathrm{Ca}_{1-\mathrm{x}} \mathrm{CO}_{3}$ solid solution grows on calcite $\{10 \overline{1} 4\}$ surfaces. The main reason for such complexity is the fact that growing surfaces are not only the simple result of the crystallization of a solid from a supersaturated solution, but they also play an important role on the whole growth processes. 

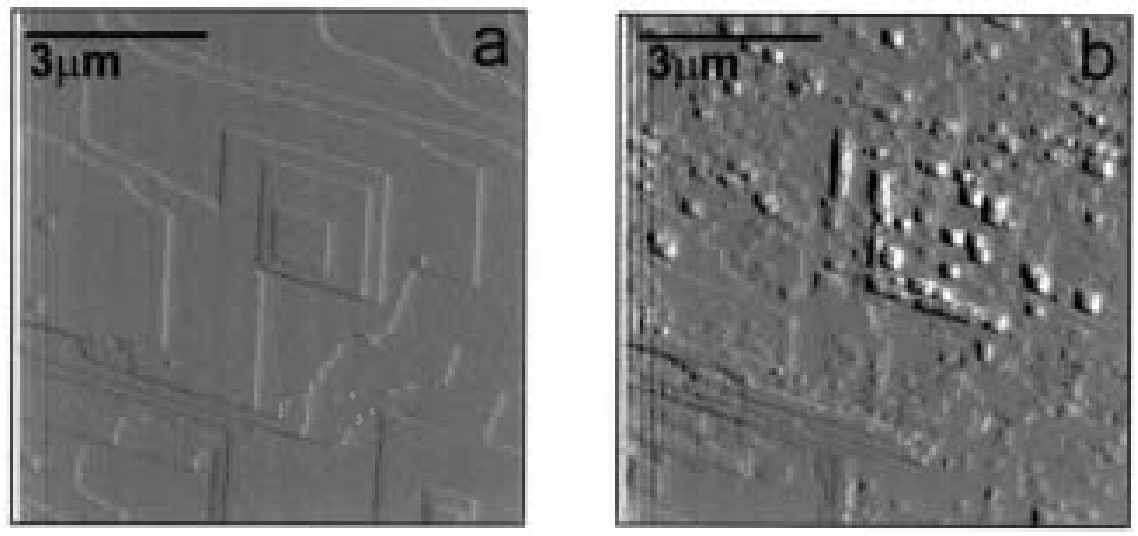

Fig. 10. (a) AFM image of a calcite $\{10 \overline{1} 4\}$ in water showing the retreat of steps and the formation of etch pits. After a few minutes of growing from solution 1 (see Table 1), the surface was covered with layers of $\mathrm{Mn}_{\mathrm{x}} \mathrm{Ca}_{1-\mathrm{x}} \mathrm{CO}_{3}$ (see Fig. 4). (b) A new injection of deionised water in the AFM fluid cell leads to the removal of the previously grown surfaces. The high density of etch pits within the newly-grown layers are related to a higher number of defects.

Although a complete elucidation of the relations between composition and microtopographic features of the surfaces in the Mn-Ca- $\bullet_{3}-\mathrm{H}_{2} \bullet$ system was beyond the scope of this work, it seems clear that the combination of in situ AFM observations, calculations based on the SS-AS theory, and surface structure models provide an adequate approach to the study of the formation of solid solutions on preexisting surfaces.

Acknewledgments-We thank the Deutsche Forschungsgemeinschaft (DFG) for financial support of this work. J. M. Astilleros thanks the Universidad Complutense de Madrid for a research grant (2000) and the European Commission for the receipt of a Marie Curie Fellowship (from July 2001). The authors appreciate the careful reviews by Dr. H. Gamsjäger, Dr. R. Reeder, an anonymous reviewer, and comments by Dr. A. Mucci.

Asseciate editer: A. Mucci

\section{REFERENCES}

Astilleros J. M., Pina C. M., Fernández-Díaz L., and Putnis A. (2000) The effect of barium on calcite $\{1014\}$ surfaces during growth. Geechim. Cosmechim. Acta 64, 2965-2972.

Astilleros J. M., Pina C. M., Fernández-Díaz L., Putnis A. (2002) Metastable phenomena on calcite $\{10 \overline{1} 4\}$ surfaces growing from $\mathrm{Sr}^{2+}-\mathrm{Ca}^{2+}-\mathrm{CO}_{3}^{2-}$ aqueous solutions Chem. Geel. (submitted)

Böttcher M. E. (1993) Die Wechselwirkungen zwischen $\mathrm{CaCO}_{3}$ $\mathrm{MnCO}_{3}$-Mischkristallen und wässerigen Läsungen: Experimentelle Untersuchungen bei $20^{\circ} \mathrm{C}$. In Sediment 93: (ed. M. R. W. Amler and K.-W. Tietz (Editors). Sediment 93. Geøl. Paläønt॰l. 15-16.

Böttcher M. E. (1997) The transformation of aragonite $\mathrm{Mn}_{\mathrm{x}} \mathrm{Ca}_{(1-\mathrm{x})} \mathrm{CO}_{3}$ solid solutions at $20^{\circ} \mathrm{C}$ : An experimental study. Mar. Chem 57, 97-106.

Brand U. and Veizer J. (1980) Chemical diagenesis of a multicomponent carbonate system-1. J. Sediment. Petrol 50, 1219-1236.

Davis K. J., Dove P. M., and De Yoreo J. J. (2000) The Role of $\mathrm{Mg}^{2+}$ as an impurity in calcite growth. Science 290, 1134-1137.

Dromgoole E. L. and Walter I. M. (1990) Inhibition of calcite growth rates by $\mathrm{Mn}^{2+}$ in $\mathrm{CaCl}_{2}$ solutions at $1 \bullet, 25$ and $50^{\circ} \mathrm{C}$. Geechim. Cesmechim. Acta 54, 2991-3000.

Fernández-González A. and Prieto M. (1999) (Ca,Mn) $\mathrm{CO}_{3}-\mathrm{H}_{2} \mathrm{O}$ : Termodinámica y conducta efectiva de cristalización en gel de ślice Bøl. Søc. Esp. Mineral 22-A, 43-44

Fernández-González A. Prieto M. (2000) Crystallisation of $(\mathrm{Ca}, \mathrm{Mn}) \mathrm{CO}_{3}$ solid solution from aqueous solutions. Euroconference on the Interaction of Mineral Surfaces with Organic and Inorganic
Species in Aqueous Solution: Experiments and Theory. Be^k of Abstracts, San Feliu de Guixols, Spain, p. 110.

Fernández-Díaz L., Putnis A., Prieto M., and Putnis C. V. (1996) The role of magnesium in the crystallization of calcite and aragonite in a porous medium. J. Sediment. Res 66, 482-491.

Fubini B. and Stone F. S. (1983) Physico-chemical properties of $\mathrm{MnCO}_{3}-\mathrm{CaCO}_{3}$ and $\mathrm{MnO}-\mathrm{CaO}$ solid solution. J. Chem. Sec. Faraday $T$ 79, 1215-1227.

Garrels R. M., Thomson M. E., and Siever R. (1960) Stability of some carbonates at $25^{\circ} \mathrm{C}$ and one atmosphere total pressure. Am. J. Sci 258, 402-418.

Goldsmith J. R. and Graf D. L. (1957) The system $\mathrm{CaO}-\mathrm{MnO}-\mathrm{CO}_{2}$ : Solid solution and decomposition reactions. Geechim. Cesmechim. Acta 11, 301-334.

Hartman P. and Perdok W. G. (1955) On the relation between structure and morphology of crystals I, II, III. Acta Crystallogr 8, 49-52 $521-529$.

Heijnen W. M. M. (1985) The morphology of gel grown calcite. $N$. $J b$. Miner. Mh 8, 357-362.

Hillner P. E., Gratz A. J., Manne S., and Hansma P. K. (1992) Atomic-scale imaging of calcite growth and dissolution in real time. Geølogy 20, 359-362.

Johnson K. S. (1982) Solubility of rhodocrosite $\left(\mathrm{MnCO}_{3}\right)$ in water and seawater. Geechim. Cesmechim. Acta 46, 1805-1809.

Lippmann F. (1973) Sedimentary Carbønate Minerals. Springer-Verlag, New York.

Lorens R. B. (1981) Sr, Cd, Mn and Co distribution coefficients in calcite as a function of calcite precipitation rate. Geechim. Cesmechim. Acta 45, 553-561.

McBeath M. K., Rock P. A., Casey W. H., and Mandell G. K. (1998) Gibbs energies of formation of metal-carbonate solid solutions: Part 3: The $\mathrm{Ca}_{x} \mathrm{Mn}_{1-\mathrm{x}} \mathrm{CO}_{3}$ system at $298 \mathrm{~K}$ and 1 bar. Geechim. Cesmechim. Acta 62, 2799-2808.

Mucci A. (1988) Manganese uptake during calcite precipitation from seawater: Conditions leading to the formation of pseudokutnahorite Geechim. Cesmechim. Acta 52, 2799-2808.

Paquette J. and Reeder R. J. (1990) New type of compositional zoning in calcite: Insights into crystal growth mechanisms. Geølogy 18, $1244-1247$

Paquette J. and Reeder R. J. (1995) Relationship between surface structure, growth mechanism, and trace element incorporation in calcite. Geechim. Cosmechim. Acta 59, 735-749.

Parker S. C., Titiloye J. O., and Watson W. (1993) Molecular modeling of carbonate minerals: Studies of growth and morphology. Philes. T. R•y. S•c. A 344, 37-48.

Pina C. M. and Putnis A. (2002) The kinetics of nucleation of solid solution from aqueous solution: A new model for calculating non- 
equilibrium distribution coefficients. Geøchim. Cøsmechim. Acta 66, 185-192.

Pina C. M., Enders M., and Putnis A. (2000) The composition of solid solutions crystallising from aqueous solutions: The influence of supersaturation and growth mechanisms. Chem. Geel. 168, 195-210

Pingitore Jr N. E., Eastman M. P., Sandige M., Oden K., and Freiha B. (1988) The coprecipitation of manganese(II) with calcite: An experimental study. Mar. Chem. 25, 107-120.

Prieto M., Putnis A., and Fernandez-Díaz L. (1993) Crystallization of solid solutions from aqueous solutions in a porous medium: Zoning in (Ba,Sr) $\mathrm{SO}_{4}$. Geel. Mag. 130, 289-299.

Putnis A., Prieto M., and Fernández-Díaz L. (1995) Fluid supersaturation and crystallisation in porous media. Geel. Mag. 132, 1-13.

Reeder R. J. (1996) Interaction of divalent cobalt, zinc, cadmium, and barium with the calcite surface during layer growth. Geechim. Cosmechim. Acta 60, 1543-1552.

Sangwal K. (1987) Etching of crystals: Theory, experiments and applications. In Defects of Selids (ed. S. Amelinckx and J. Nihoul), p. 15, North Holland Physics.

Sangwal K. (1993) Effect of impurities on the processes of crystal growth. J. Cryst. Growth 128, 1236-1244.

Söhnel O. (1982) Electrolyte crystal-aqueous solution interfacial tensions from crystallization data. $J$. Cryst. Grewth 57, 101-108.

Staudt W. J. and Reeder R. J. (1994) Surface structural controls on compositional zoning of $\mathrm{SO}_{4}{ }^{2-}$ and $\mathrm{SeO}_{4}{ }^{2-}$ in synthetic calcite crystals. Ge•chim. Cosmechim. Acta 58, 2087-2098.

Stumm W. Morgan J. J. (1981) Aquatic Chemistry. An Introduction Emphasizing Chemical Equilibria in Natural Waters. Wiley-Interscience, New York.
Sunagawa I. (1987) Morphology of minerals. In Merphølegy •fCrystals (ed. I. Sunagawa), vol. 2, pp. 511-587, Terra Scientific Publishing Company (TERRAPUB), Tokyo.

Temman M., Paquette J., and Vali H. (2000) Mn and Zn incorporation into calcite as a function of chloride aqueous concentration. Geechim. Cesmechim. Acta 64, 2417-2430.

Ten Have T. and Heijnen W. (1985) Catholuminiscence activation and zonation in carbonate rocks: An experimental approach. Geel. Miinbøuw 64, 297-310.

Teng H. H., Dove P. M., Orme C., De Yoreo J. J. (1997) Microscopic characterization of mechanisms and fundamental parameters governing calcite mineralisation. Seventh Annual V. M. Geldschmidt Conference, Tucson, Arizona, 1997, pp. 204-205 (abstracts).

Tesoriero A. J. and Pankow J. F. (1996) Solid solution partitioning of $\mathrm{Sr}^{2+}, \mathrm{Ba}^{2+}$, and $\mathrm{Cd}^{2+}$ to calcite. Geøchim. Cesmechim. Acta 60 , 1053-1063.

Truesdel H. A. and Jones B. F. (1974) WATEQ, a computer program for calculating chemical equilibria of natural waters. USGS J. Res. 2 , 233-248.

Van Cappellen P., Charlet L., Stumm W., and Wersin P. (1993) A surface complexation model of the carbonated mineral-aqueous solution interface. Geechim. Cesmechim. Acta 57, 3505-3518.

Wagman D., Evans W. H., Parker V. B., Schumm R. H., Hallow I., Bailey S. M., Chumey K. L., and Nuttall R. L. (1982) The NBS tables of chemical thermodynamic properties: Selected values for inorganic and $\mathrm{C} 1$ and $\mathrm{C} 2$ organic substances in SI units. J. Phys. Chem. Ref. Data 11: Suppl 2.

Wu W. and Nancollas G. H. (1999) Determination of interfacial tension from crystallization and dissolution data: A comparison with other methods. Adv. Colloid Interfac 79, 229-279. 